\title{
THE EFFECTS OF THERAPY ON PULMONARY MECHANICS IN HUMAN PULMONARY EDEMA*
}

\author{
By JOHN TURNER SHARP, $\dagger$ IVAN L. BUNNELL, GERAINT T. GRIFFITH $\ddagger$ \\ AND DAVID G. GREENE
}

\author{
(From the Department of Medicine of the Buffalo General Hospital and the University of \\ Buffalo School of Medicine, Buffalo, N. Y.)
}

(Submitted for publication October 3, 1960; accepted December 13, 1960)

We have previously described pulmonary mechanics in human pulmonary edema (1). The present report deals with the effects of morphine, aminophylline and positive pressure breathing on the altered pulmonary mechanics of patients with acute pulmonary edema.

\section{METHODS}

Patients selected for study had acute pulmonary edema as defined by the presence of: 1) moderate to marked dyspnea at rest ; 2) moist rales over at least one-half of both lung fields in the absence of fever or other signs of pulmonary infection; 3) evidence of incapacitating heart disease with previous episodes of pulmonary congestion or edema; 4) roentgenographic changes consistent with pulmonary edema. Of the 6 patients studied, 3 had arteriosclerotic heart disease, 2 had chronic rheumatic valvular disease, and 1 had hypertensive cardiovascular disease.

As soon as possible after the diagnosis of pulmonary edema had been made, pulmonary compliance and resistance were measured repeatedly over a 20 to $30 \mathrm{~min}$ ute period prior to the use of therapeutic agents to establish the variability of these measurements over short periods of time. Following the control observations, a single therapeutic agent was given and measurements repeated at intervals varying from 1 to 10 minutes. All observations were made with patients sitting in bed. Morphine and aminophylline were given intravenously in doses of $10 \mathrm{mg}$ and $0.5 \mathrm{~g}$, respectively. In following the effects of these two agents, observations were made over periods of 25 to 30 minutes following administration. Positive pressure breathing was given through a plastic mouthpiece connected in series with a screen pneumotachograph and positive pressure breathing valve. Compressed air rather than oxygen was used in order to

\footnotetext{
* Supported by grants-in-aid from the American Heart Association and the Surgeon General of the Army.

$\dagger$ This work was carried out during tenure of an Established Investigatorship of the American Heart Association. Dr. Sharp's present address is the Cardiopulmonary Laboratory, Veterans Administration Hospital, Hines, Ill.

$\ddagger$ This work was carried out during tenure of a Research Fellowship of the American Heart Association.
}

avoid confusing the therapeutic effect of positive pressure breathing with that of oxygen. The pneophore valve was set for peak expiratory pressures of 15 to $20 \mathrm{~cm}$ of water and was adjusted to the highest levels which could be comfortably tolerated by the patient and which did not depress the blood pressure. ${ }^{1}$ Mean airway (mouthpiece) pressure averaged $+7 \mathrm{~cm} \mathrm{H}_{2} \mathrm{O}$, peak expiratory pressure, $+17 \mathrm{~cm} \mathrm{H}_{2} \mathrm{O}$, and mean expiratory pressure, $+12 \mathrm{~cm} \mathrm{H}_{2} \mathrm{O}$. A typical record obtained during positive pressure breathing is shown in Figure 1. Pulmonary compliance was measured before, during, and after positive pressure breathing as indicated in Figures 1 and 3. Pulmonary resistance was measured before and during positive pressure breathing.

Esophageal pressure was recorded in early experiments through a water-filled polyethylene catheter, 60 $\mathrm{cm}$ long, with an internal diameter of $0.09 \mathrm{~cm}$ attached to a pressure transducer of low volume displacement, and in later experiments through an air-filled balloon catheter (balloon length $15 \mathrm{~cm}$ ) similar to that described by Mead, McIlroy, Selverstone and Kriete (2). Through use of pressure transducers of low volume displacement, the response characteristics of both esophageal pressure recording systems were adequate. The tip of the catheter in each case lay in the upper or middle third of the esophagus. Airflow was recorded by measuring the differential pressure across a 400 mesh Monel metal screen, 2 inches in diameter. In early experiments the tidal volume was measured in a standard $7 \mathrm{~L}$ spirometer to the counterweight of which was attached an electrical contact to a resistance wire. This resistance wire formed two arms of a resistance bridge which was activated by a mercury cell, the output of which was fed into a DC amplifier. In later experiments, a low inertia Krogh spirometer was used, at the fulcrum of which was attached an angular displacement transducer of linear characteristics. During positive pressure breathing the mouth pressure was also recorded, as shown in Figures

1 The pneophore valve, manufactured by Mine Safety Appliances, Inc., is a pressure-cycled device providing positive pressure during inspiration and expiration. The expiratory pressure at which the valve is set is the peak end-inspiratory pressure which trips the valve, initiating expiration. The top tracings in Figures 1 and 2 are mouth pressures recorded during use of this valve, and their examination may clarify concepts of the valve's operation. 


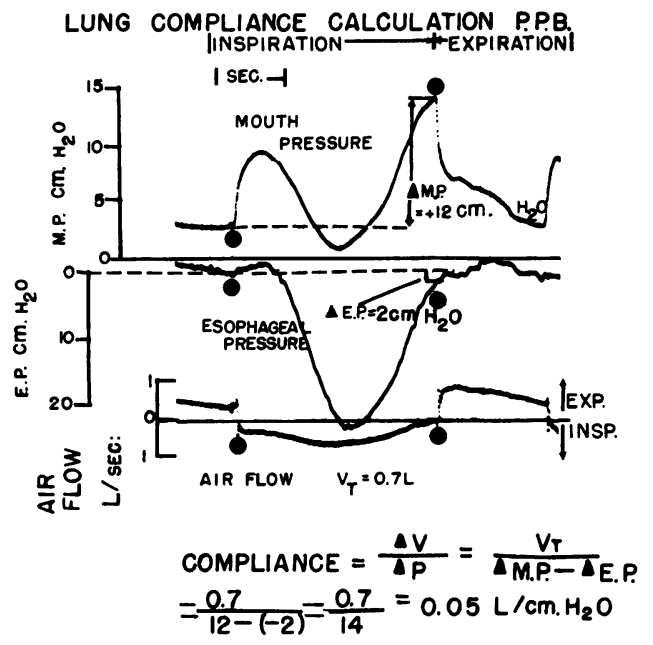

Fig. 1. The calculation of LUNG COMPliance durING POSITIVE PRESSURE BREATHING (P.P.B.) FROM TRACINGS OF MOUTH PRESSURE, ESOPHAGEAL PRESSURE AND AIRFLOW. The tidal volume is determined by integration of the area under the airflow curve. The large solid dots indicate points of zero airflow. It will be noted that inasmuch as compliance equals $\Delta \mathrm{V}$ divided by $\Delta \mathrm{P}$, absolute values of esophageal and mouth pressures need not be known so long as static pressures at the beginning and end of inspiration are known.

1 and 2 , and the tidal volume was obtained by integration of the pneumotachographic tracing.

Pulmonary compliance during both ambient pressure and positive pressure breathing was obtained by dividing the tidal volume by the change in static transpulmonary pressure. During ambient pressure breathing, tidal volume was divided by the difference between static endexpiratory and static end-inspiratory esophageal pressure. The calculation of pulmonary compliance during positive pressure breathing (P.P.B) is shown in Figure 1. Pulmonary compliance $=\frac{\text { tidal volume }}{\Delta \text { M.P. }-\Delta E . P \text {. where }}$ $\Delta$ M.P. and $\Delta$ E.P. are the changes in mouth pressure and esophageal pressure, respectively, between points of zero flow (indicated by the large solid dots) at the beginning and at the end of an inspiration. The expression ( $\Delta$ M.P. $-\Delta$ E.P.) is the change in static transpulmonary pressure and is obtained by subtracting algebraically the esophageal pressure from the mouth pressure as shown in the sample calculation in Figure 1. It will be noted that absolute pressure need not be known, only the change in transpulmonary pressure; points of zero airflow are used for reference.

In the studies of the effect of positive pressure breathing on 2 normal subjects, the volume, in addition to being calculated by integration of the flow curve as was done in the pulmonary edema patients, was also directly measured by having the patient lie prone in a horizontal body plethysmograph.

Pulmonary resistance was calculated at points of $0.5 \mathrm{~L}$ per second airflow by the method of von Neergaard and Wirz (3), which method gives a resistance value representing the sum of airway and lung tissue resistances. The method, modified somewhat to permit calculation of pulmonary resistance during positive pressure breathing is shown in Figure 2. Pulmonary resistance $=\mathrm{P}_{\mathrm{r}} / \mathrm{V}$, where $\mathrm{Pr}$ is the resistive component of the pressure difference between pleural space (or esophagus) and mouth at any time during inspiration, and $\mathrm{V}$ is the simultaneous airflow. $P_{r}$ at time $x$ in the figure, at which time volume $V_{x}$ has entered the lungs, is ( $\Delta$ M.P. $\left.-\Delta E . P.\right)$ $-\Delta \mathrm{P}_{\mathrm{c}} . \quad \Delta \mathrm{P}_{\mathrm{c}}$ is the static transpulmonary pressure or that pressure necessary to distend the lung statically to volume $V_{x}$ and is obtained by dividing the volume $V_{x}$ by the lung compliance (previously calculated for this breath, as in Figure 1). Absolute pressures need not be known, since the end-expiratory volume and pressure are used as the "zero" reference points for this calculation. Compliance and resistance values are averages of values obtained from 6 to 10 breaths.

\section{RESULTS}

The effects of positive pressure breathing. Table I presents data on the three subjects in whom positive pressure breathing was evaluated. Pulmonary compliance during positive pressure breathing was consistently higher than that during ambient

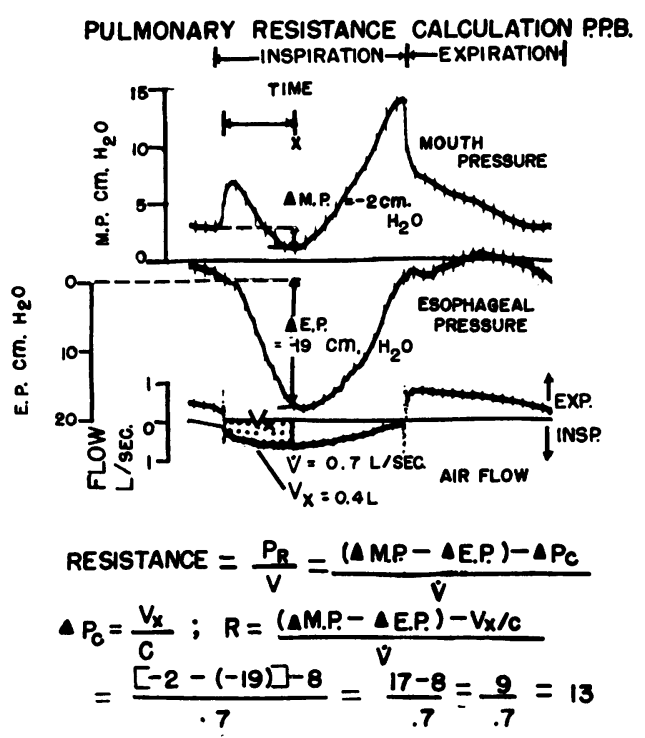

Fig. 2. The calculation of pUlmonary Resistance DURING POSITIVE PRESSURE BREATHING FROM SIMULTANEOUS TRACINGS OF ESOPHAGEAL PRESSURE, MOUTH PRESSURE AND AIRFLow. The volume which has entered the lungs at time $x, V_{x}$, is obtained by integrating the area under the airflow curve from the beginning of inspiration to time $x$. Resistance is expressed in $\mathrm{cm}_{2} \mathrm{O} / \mathrm{L} / \mathrm{sec}$. The pulmonary compliance, necessary to determine $\Delta \mathrm{P}_{\mathrm{c}}$, is calculated as shown in Figure 1. 
TABLE I

The effects of positive pressure breathing (P.P.B.) on pulmonary mechanics *

\begin{tabular}{|c|c|c|c|c|c|}
\hline Patient & Measurement & Before P.P.B. & During P.P.B. & After P.P.B. & $\mathrm{p}$ \\
\hline \multicolumn{6}{|c|}{ Pulmonary edema patients } \\
\hline M.O. & $\begin{array}{l}\text { Compliance } \\
\text { Insp. resistance } \\
\text { Exp. resistance } \\
\text { Resp. rate } \\
\text { Tidal volume }\end{array}$ & $\begin{array}{cl}0.035 & \pm 0.0009 \\
12.1 & \pm 1.0 \\
13.3 & \pm 1.8 \\
19 & \\
0.70 & \end{array}$ & $\begin{array}{cl}0.049 & \pm 0.0013 \\
14.2 & \pm 1.6 \\
8.0 & \pm 0.43 \\
18 & \\
0.60 & \end{array}$ & $\begin{array}{l}0.039 \pm 0.0016 \\
22 \\
0.67\end{array}$ & $\begin{array}{l}<0.01 \\
>0.05 \\
<0.05\end{array}$ \\
\hline F.S. & $\begin{array}{l}\text { Compliance } \\
\text { Insp. resistance } \\
\text { Exp. resistance } \\
\text { Resp. rate } \\
\text { Tidal volume }\end{array}$ & $\begin{array}{ll}0.045 & \pm 0.0008 \\
11.6 & \pm 1.1 \\
11.4 & \pm 0.7 \\
21 & \\
0.65 & \end{array}$ & $\begin{array}{ll}0.065 & \pm 0.0029 \\
10.5 & \pm 0.84 \\
11.7 & \pm 1.07 \\
21 & \\
0.64 & \end{array}$ & $\begin{array}{l}0.0057 \pm 0.001 \\
22 \\
0.63\end{array}$ & $\begin{array}{l}<0.01 \\
>0.0 \\
>0.05\end{array}$ \\
\hline H.L. & $\begin{array}{l}\text { Compliance } \\
\text { Insp. resistance } \\
\text { Exp. resistance } \\
\text { Resp. rate } \\
\text { Tidal volume }\end{array}$ & $\begin{array}{cl}0.057 & \pm 0.001 \\
10.1 & \pm 0.3 \\
11.1 & \pm 0.6 \\
20 & \\
0.95 & \end{array}$ & $\begin{array}{cl}0.075 & \pm 0.0024 \\
12.3 & \pm 0.9 \\
13.6 & \pm 0.9 \\
19 & \\
0.68 & \end{array}$ & $\begin{array}{l}0.054 \pm 0.0021 \\
20 \\
0.50\end{array}$ & $\begin{array}{l}<0.01 \\
<0.05 \\
<0.05\end{array}$ \\
\hline \multicolumn{6}{|c|}{ Normals } \\
\hline D.Ra. & $\begin{array}{l}\text { Compliance } \\
\text { Resp. rate } \\
\text { Tidal volume }\end{array}$ & $\begin{array}{l}0.367 \pm 0.022 \\
21 \\
1.33\end{array}$ & $\begin{array}{l}0.316 \pm 0.109 \\
20 \\
0.72\end{array}$ & & $>0.05$ \\
\hline D. Rm. & $\begin{array}{l}\text { Compliance } \\
\text { Resp. rate } \\
\text { Tidal volume }\end{array}$ & $\begin{array}{l}0.119 \pm 0.005 \\
21 \\
0.79\end{array}$ & $\begin{array}{l}0.134 \pm 0.006 \\
23 \\
0.84\end{array}$ & & $>0.05$ \\
\hline
\end{tabular}

* Pulmonary compliance is expressed in $\mathrm{L} / \mathrm{cm} \mathrm{H}_{2} \mathrm{O}$; pulmonary resistance in $\mathrm{cm} \mathrm{H}_{2} \mathrm{O} / \mathrm{L} / \mathrm{sec}$; respiratory rate in breaths/min; tidal volume in L. Standard errors of the mean for compliance and resistance measurements are given (see text for discussion).

pressure spontaneous breathing. These increases in lung compliance could not be explained by changes in respiratory frequency or by tidal volume changes. Data for Patient H.L., which are representative of the three patients, are illustrated in Figure 3. The increases in lung compliance over the initial values for the three patients were 44, 40 and 24 per cent, averaging 36 per cent. There was also a trend for the compliance values after positive pressure breathing to be higher than those before positive pressure breathing. Data on the two normal subjects, showing no significant changes in compliance on positive pressure breathing, are shown in the lower portion of Table $\mathrm{I}$. A small but significant increase in both inspiratory and expiratory resistance was observed in one patient during positive pressure breathing and a significant decrease in expiratory resistance in another.

The effect of intravenous aminophylline. The pulmonary compliance consistently and significantly increased following intravenous aminophylline in the three patients studied (Table II and

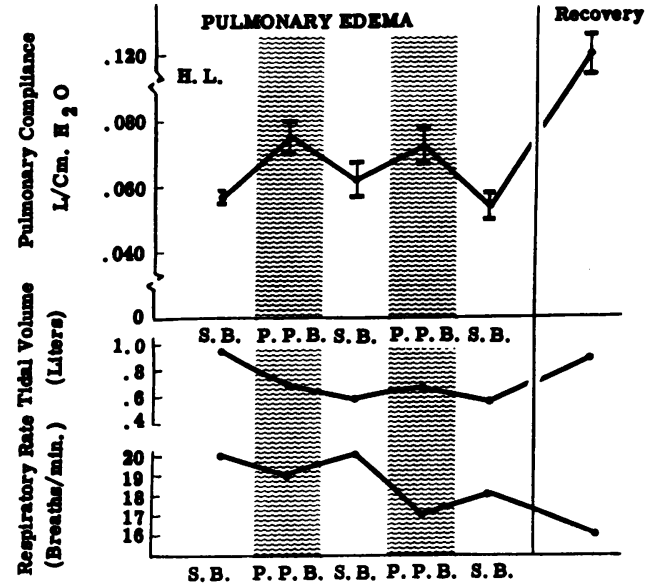

Fig. 3. The efFects of positive pressure bReathing ON LUNG COMPLIANCE IN A PATIENT WITH PULMONARY EDEMA. Ten-minute periods of positive pressure breathing (P.P.B.) are alternated with periods of spontaneous ambient pressure breathing (S.B.). Lung compliance rises significantly during positive pressure breathing, but falls again on cessation of positive pressure breathing. No consistent changes in tidal volume or respiratory rate accompanied the compliance changes. Brackets indicate $\pm 2 \mathrm{SE}$. 
TABLE II

The acute effects of intravenous aminophylline on pulmonary mechanics in pulmonary edema*

\begin{tabular}{|c|c|c|c|c|}
\hline Patient & Measurement & $\begin{array}{l}\text { Before amino- } \\
\text { phylline }\end{array}$ & $\begin{array}{l}\text { After amino- } \\
\text { phylline }\end{array}$ & $\mathrm{p}$ \\
\hline F.W. & $\begin{array}{l}\text { Compliance } \\
\text { Insp. resistance } \\
\text { Resp, rate } \\
\text { Tidal volume }\end{array}$ & $\begin{array}{c}0.033 \pm 0.0022 \\
10.8 \pm 0.83 \\
31 \\
0.55\end{array}$ & $\begin{array}{l}0.046 \pm 0.0018 \\
6.5 \pm 0.71 \\
32 \\
0.64\end{array}$ & $\begin{array}{l}<0.01 \\
<0.01\end{array}$ \\
\hline J.C. & $\begin{array}{l}\text { Compliance } \\
\text { Insp. resistance } \\
\text { Resp. rate } \\
\text { Tidal volume }\end{array}$ & $\begin{array}{l}0.029 \pm 0.0015 \\
12.0 \pm 0.58 \\
34 \\
0.28\end{array}$ & $\begin{array}{l}0.041 \pm 0.0021 \\
9.0 \pm 0.05 \\
33 \\
0.35\end{array}$ & $\begin{array}{l}<0.01 \\
<0.01\end{array}$ \\
\hline P.N. & $\begin{array}{l}\text { Compliance } \\
\text { Insp. resistance } \\
\text { Exp. resistance } \\
\text { Resp. rate } \\
\text { Tidal volume }\end{array}$ & $\begin{array}{c}0.073 \pm 0.0021 \\
6.5 \quad \pm 0.57 \\
5.3 \quad \pm 0.93 \\
33 \\
0.70\end{array}$ & \begin{tabular}{cc}
\multicolumn{2}{c}{$0.108 \pm 0.0091$} \\
3.5 & \pm 0.12 \\
2.4 & \pm 0.78 \\
28 & \\
0.74 &
\end{tabular} & $\begin{array}{l}<001 \\
<0.01 \\
<0.05\end{array}$ \\
\hline
\end{tabular}

* See footnote to Table I.

Figure 4). These increases could not be explained by coincident changes in tidal volume or respiratory rate. Pulmonary resistance consistently decreased after aminophylline (Table II). Both compliance and resistance changes following aminophylline administration are significant with $\mathrm{p}$ values well under 0.05 and most under 0.01 .

The effects of intravenous morphine. Figure 5 represents typical data before and after the in-

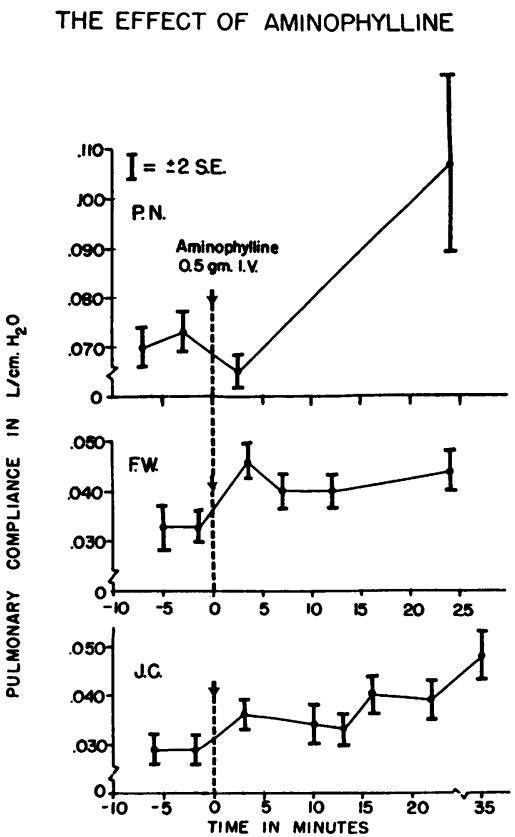

Fig. 4. Tile efFect of intravenous aminopitylline ON PULMONARY COMPLIANCE IN THREE PATIENTS WITH PULMONARY EDEMA. Significant increases in pulmonary compliance were seen in all three patients. Brackets indicate $\pm 2 \mathrm{SE}$. travenous administration of morphine. No significant changes in compliance occurred despite moderate fluctuations in tidal volume and rate. The three patients all showed a central depressant effect following morphine and all described some degree of subjective clinical improvement. Compliance data for these three patients are shown in Table III. It is apparent that morphine had no demonstrable effects upon lung compliance in these three patients. Pulmonary resistance was not significantly different before and after morphine either during inspiration or during expiration, except in one patient during inspiration only.

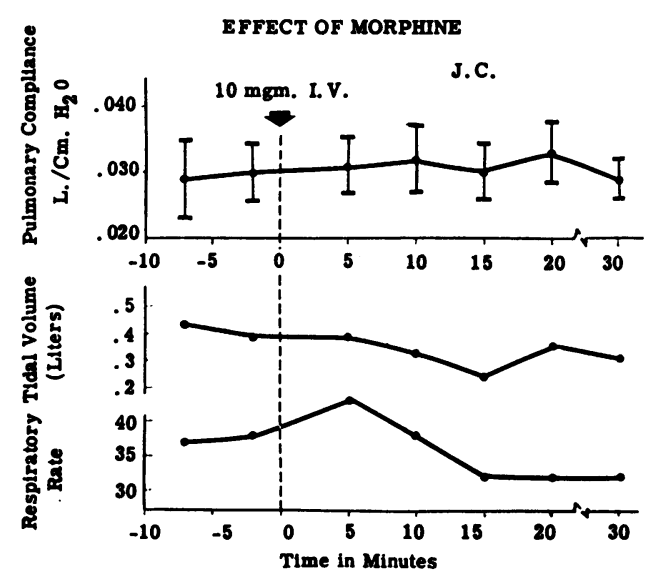

Fig. 5. The efFect OF INTRAVENOUS MORPhine ON PULMONARY COMPLIANCE IN A PATIENT WITH ACUTE PULMONARY EDEMA. There were no significant changes in pulmonary compliance, although the respiratory rate and tidal volume fell slightly following morphine. Brackets indicate $\pm 2 \mathrm{SE}$.

\section{DISCUSSION}

Positive pressure breathing. Butler and Smith (4) concluded from their data that compliance measured during positive pressure inflation of the lungs is lower than that measured during spontaneous breathing. They suggested that this may be due to inflation (and perhaps overinflation) of the more central and directly accessible alveoli which compress the peripheral alveoli, removing them from the effective alveolar volume. Their data, however, were obtained from unconscious paralyzed subjects who were ventilated passively. Under their experimental conditions their hypothesis may be true. Our subjects, however, being conscious, were initiating their own respiration and doing much of their own respiratory work 
during positive pressure breathing. This may account for the fact that, in contrast to what is inferred in Butler and Smith's study, the lung compliance in our normal subjects changed insignificantly during positive pressure breathing.

Figure 6 illustrates one explanation for the increase in compliance during positive pressure breathing found in pulmonary edema. The respiratory midposition is known to shift upward (the functional residual capacity increases) during positive pressure breathing, as indicated in the figure. Data published by Whittenberger and Affeldt (5), by Cook and associates (6), and from our laboratory ( 7$)$ indicate that the static volume-pressure curve or compliance curve of

TABLE III

The acute effects of intravenous morphine on pulmonary mechanics in pulmonary edema *

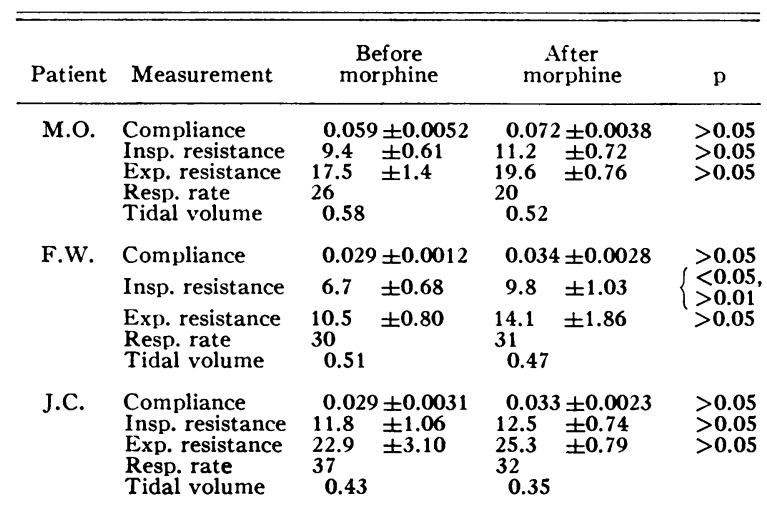

* See footnote to Table I.

the lung is not linear in pulmonary edema. This nonlinearity is thought to be caused by fluid menisci or fine bubbles in alveoli and minute airways and to closure of terminal lung units by other mechanisms. Given this curvilinearity, the compliance value depends on where on the volumepressure curve lung compliance is measured. It will be noted from the bottom portion of Figure 6 that merely elevating the level at which tidal breathing takes place increases lung compliance. A similar upward shift produces no such change in normal subjects because of the linear nature of most of the normal volume-pressure curve. Evidence from the present data which suggests that this mechanism is involved in the compliance increase found during positive pressure breathing is presented in Table IV. We previously de-

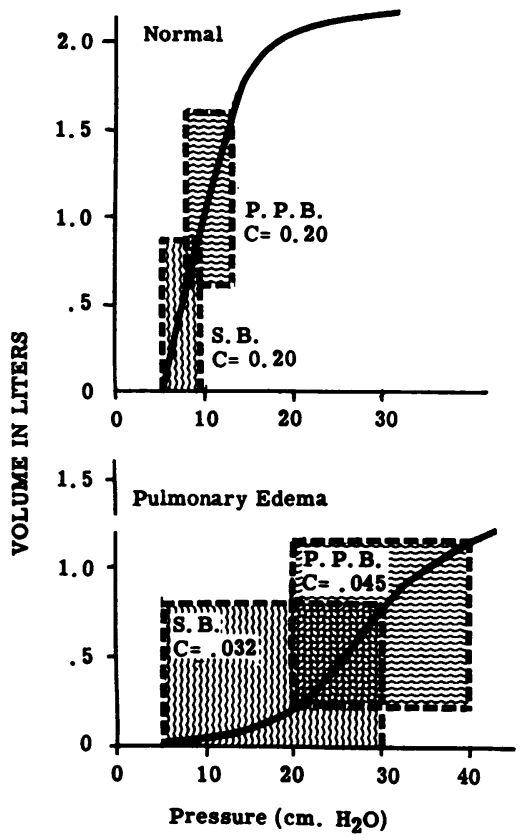

Fig. 6. ONe explanation FOR THE INCREASE IN PULMONARY COMPLIANCE DURING POSITIVE PRESSURE BREATHING IN PULMONARY EDEMA. The respiratory midposition is known to shift upward during positive pressure breathing. Such an upward shift on the nonlinear static volume-pressure curve (compliance curve) of a patient in pulmonary edema would result in an increased compliance as seen in the lower panel. Because of the linearity of the normal volume-pressure curve, a similar shift would produce no such change in lung compliance in normal subjects (upper panel).

TABLE IV

The difference between early inspiratory resistance and late inspiratory resistance during ambient pressure breathing as compared with positive pressure breathing in three patients with pulmonary edema*

\begin{tabular}{lccc}
\hline \hline Patient & Early insp. & Late insp. & $\mathrm{p}$ \\
\hline \multicolumn{4}{c}{ During ambient pressure breathing } \\
F.S. & $16.2 \pm 0.3$ & $7.1 \pm 0.3$ & $<0.01$ \\
H.L. & $14.9 \pm 1.06$ & $11.4 \pm 0.54$ & $<0.05$ \\
M.O. & $17.9 \pm 2.4$ & $12.5 \pm 1.0$ & $<0.10 \stackrel{>}{>} 0.05$ \\
\multicolumn{5}{c}{ During positive pressure breathing } \\
F.S. & $11.5 \pm 0.39$ & $10.5 \pm 0.84$ & $>0.05$ \\
H.I. & $12.8 \pm 0.51$ & $12.3 \pm 0.88$ & $>0.05$ \\
M.O. & $14.2 \pm 1.63$ & $18.8 \pm 0.68$ & $<0.05$ \\
\hline
\end{tabular}

* Pulmonary resistance was measured at $0.5 \mathrm{~L} / \mathrm{sec}$ airflow during the first $0.2 \mathrm{sec}$ (designated as early inspiratory resistance) and during the last $0.2 \mathrm{sec}$ (designated as late inspiratory resistance) of inspiration. Resistance is expressed in $\mathrm{cm} \mathrm{H}_{2} \mathrm{O} / \mathrm{L} / \mathrm{sec}$. During ambient pressure breathing, resistance is consistently higher early in inspiration than it is later in inspiration. During positive pressure breathing this difference is less striking (and insignificant) in two cases and reversed in the third (M.O.). Standard errors of the mean are shown (see text for discussion). 
scribed (1) a high early inspiratory resistance in pulmonary edema. We suggested that this was probably a falsely high resistance value because of the assumption (here probably false) necessary for the resistance calculation that the compliance is the same at all volumes (or that the volumepressure or compliance curve is linear). The upper portion of Table IV demonstrates the high early inspiratory resistance in three patients during ambient pressure breathing. The lower half of the table shows that early and late inspiratory resistances are more nearly the same during positive pressure breathing, suggesting, as diagrammed in Figure 6, that compliance is more nearly uniform and the volume-pressure curve more nearly linear following this upward shift in respiratory midposition.

Other reasons for an increase in lung compliance during positive pressure breathing are related, as Barach, Martin and Eckman (8) described in 1938, to the fact that positive pressure breathing diminishes the return of venous blood to the right heart and hence reduces pulmonary blood volume. Recently Kilburn and Sieker (9) have confirmed that the central blood volume decreases in normal subjects during positive pressure breathing. Several authors $(10,11)$ have demonstrated that pulmonary compliance falls as pulmonary capillary pressure (and inferentially pulmonary blood volume) rises. An incidental observation that rales are less prominent and often absent during positive pressure breathing, although returning quite promptly after cessation of positive pressure breathing, would suggest rapid clearing of edema fluid from finer airways and possibly from alveoli.

Effect of aminophylline. Aminophylline given intravenously in doses of $0.5 \mathrm{~g}$ appears to have a measurable effect upon pulmonary compliance and pulmonary resistance. Although two of three patients in whom aminophylline was used were hypertensive, in neither was there a fall in systemic blood pressure following aminophylline sufficient to reverse left ventricular failure. Aminophylline is known to have an effect upon the bronchial musculature, the myocardium, and the pulmonary vascular bed (12). The first of these actions is probably responsible for the changes in resistance shown in the present data (Table II). Selective improvement in the efficiency of the left ventricle may be an important mechanism in explaining its action. Pulmonary vasodilatation would be beneficial if it selectively dilated pulmonary veins and venules, increasing the capacity of the pulmonary vascular bed and relieving obstruction to the outflow of blood from the lungs. In certain types of experimental pulmonary edema, notably those produced by the administration of gram-negative bacterial endotoxin (13), histamine and serotonin $(14,15)$, pulmonary venoconstriction has been demonstrated.

Effect of morphine. The fact that we have been unable to demonstrate an acute effect of morphine on lung compliance in pulmonary edema suggests that this agent, of proven therapeutic value in clinical pulmonary edema, must act by some mechanism other than a direct effect upon the physical properties of the respiratory system. It should be noted that, in the dosage used, morphine had no consistent effect upon tidal volume or respiratory rate. It has been suggested by Drinker (16) that rapid shallow breathing favors lymphatic stasis in the lungs, whereas slower, deeper breathing favors accelerated lymph drainage from the lungs. It may be that morphine in this study was used in doses too small to produce the slowed respiratory rate often seen when this agent is used in clinical pulmonary edema. These patients did, however, show a central depressant effect following the drug, and despite the fact that no measurable change in lung compliance was apparent, the patients were more comfortable following morphine. Morphine may act by reducing oxygen requirements through elimination of anxiety with its useless, oxygen-wasting muscular activity, although no published data are available on this point. Luisada (17) has suggested that morphine acts by depressing central nervous pathways which may be responsible for the initiation or perpetuation of pulmonary edema. However, he does not present convincing evidence in the reference cited or in a later review (18) as to what central pathways are involved or by what mechanisms their activity produces or perpetuates pulmonary edema. He cites the beneficial effect of morphine and other sedatives as indirect evidence of the importance of neurogenic mechanisms in pulmonary edema. Our data neither confirm nor deny the importance of neurogenic mecha- 
nisms and give no answer to the question of how morphine acts.

Rodbard (19) has suggested that the beneficial effects of morphine may depend upon its bronchoconstrictive action which would raise alveolar pressure and thus produce an intrinsic positive pressure mechanism. The mean alveolar pressure would indeed be raised if pulmonary resistance were greater during expiration than during inspiration, a situation which is present in emphysema and asthma due to other mechanisms (20, 21), but not consistently in pulmonary edema where inspiratory resistance often equals or exceeds expiratory resistance (1). In Table III all three patients had higher pulmonary resistances during expiration than during inspiration. However, following morphine a significant increase in inspiratory resistance occurred in only one patient and in none did a significant increase in expiratory resistance occur. Relative to Rodbard's hypothesis, the occurrence, rather atypically, of a higher pulmonary resistance during expiration than during inspiration, makes the mechanism possible in these three patients. However, the absence of demonstrable bronchoconstrictive effect, selectively expiratory or otherwise, renders untenable in these patients Rodbard's explanation for the beneficial effect of morphine (19).

\section{CONCLUSIONS}

1. In six patients with acute pulmonary edema, the effects upon pulmonary compliance and resistance of positive pressure breathing, intravenous aminophylline, and intravenous morphine have been assessed.

2. In three patients with acute pulmonary edema, pulmonary compliance rose acutely by an average of 36 per cent during positive pressure breathing (P.P.B.), falling to or toward control levels following cessation of P.P.B. P.P.B. produced no consistent change in pulmonary resistance.

3. Intravenous aminophylline was followed by significant acute increases in pulmonary compliance and by significant and prompt decreases in pulmonary resistance in three patients with acute pulmonary edema.

4. Intravenous morphine had no significant effect on either pulmonary compliance or pulmonary resistance in three patients with acute pulmonary edema.

\section{ACKNOWLEDGMENT}

The authors gratefully acknowledge helpful criticism and advice from Doctors Jere Mead, Simon Rodbard and Armand Littman.

\section{REFERENCES}

1. Sharp, J. T., Griffith, G. T., Bunnell, I. L., and Greene, D. G. Ventilatory mechanics in pulmonary edema in man. J. clin. Invest. 1958, 37, 111.

2. Mead, J., McIlroy, M. B., Selverstone, N. J., and Kriete, B. C. Measurement of intraesophageal pressure. J. appl. Physiol. 1955, 7, 491.

3. von Neergaard, J., and Wirz, K. Die Messung der Strömungswiderstände in den Atemwegen des Menschen, insbesondere bei Asthma und Emphysem. Z. klin. Med. 1927, 105, 51.

4. Butler, J., and Smith, B. H. Pressure-volume relationships of the chest in completely relaxed anaesthetised patient. Clin. Sci. 1957, 16, 125.

5. Whittenberger, J. L., and Affeldt, J. E. Aspects of pulmonary physiology which determine the effectiveness of artificial respiration procedures. Army Chemical Corps Medical Division, Special Report no. 5, 1951, p. 39.

6. Cook, C. D., Mead, J., Schreiner, G. L., Frank, N. R., and Craig, J. M. Pulmonary mechanics during induced pulmonary edema in anesthetized dogs. J. appl. Physiol. 1959, 14, 177.

7. Greene, D. G., Sharp, J. T., Reisman, R. E., and Westinghouse, W. J. Evaluation of pulmonary edema (abstract). Amer. J. Physiol. 1955, 183, 622.

8. Barach, A. L., Martin, J., and Eckman, M. Positive pressure respiration and its application to the treatment of acute pulmonary edema. Ann. intern. Med. 1938, 12, 754.

9. Kilburn, K. H., and Sieker, H. O. Hemodynamic effects of continuous positive and negative pressure breathing in normal man. Circulat. Res. 1960, 8, 660.

10. Saxton, G. A., Jr., Rabinowitz, M., Dexter, L., and Haynes, F. The relationship of pulmonary compliance to pulmonary vascular pressures in patients with heart disease. J. clin. Invest. 1956, 35, 611.

11. Borst, H. G., Berglund, E., Whittenberger, J. L., Mead, J., McGregor, M., and Collier, C. The effect of pulmonary vascular pressures on the mechanical properties of the lungs of anesthetized dogs. J. clin. Invest. 1957, 36, 1708.

12. Quimby, C. W., Jr., Aviado, D. M., Jr., and Schmidt, C. F. The effect of aminophylline and other xanthines on the pulmonary circulation. J. Pharmacol. exp. Ther. 1958, 122, 396. 
13. Kuida, H., Hinshaw, L. B., Gilbert, R. P., and Visscher, M. B. Effect of gram-negative endotoxin on pulmonary circulation. Amer. J. Physiol. 1958, 192, 335.

14. Gilbert, R. P., Hinshaw, L. B., Kuida, H., and Visscher, M. B. Effects of histamine, 5-hydroxytryptamine and epinephrine on pulmonary hemodynamics with particular reference to arterial and venous segment resistances. Amer. J. Physiol. 1958, 194, 165.

15. Aviado, D. M. Pulmonary venular responses to anoxia, 5-hydroxytryptamine and histamine. Amer. J. Physiol. 1960, 198, 1032.

16. Drinker, C. K. Pulmonary Edema and Inflammation. Cambridge, Harvard University Press, 1945.
17. Luisada, A. Neue Untersuchungen über die Wirkung des Morphiums auf Blutgefässe, besonders Lungengefässe. Arch. exp. Path. Pharmak. 1928, 132, 296.

18. Luisada, A. A. The pathogenesis of paroxysmal pulmonary edema. Medicine (Baltimore) 1940, 19, 475.

19. Rodbard, S. Bronchomotor tone; a neglected factor in regulation of pulmonary circulation. Amer. J. Med. 1953, 15, 356.

20. Dayman, $H$. Mechanics of airflow in health and in emphysema. J. clin. Invest. 1951, 30, 1175.

21. Fry, D. L., Ebert, R. V., Stead, W. W., and Brown, C. C. The mechanics of pulmonary ventilation in normal subjects and in patients with emphysema. Amer. J. Med. 1954, 16, 80. 